\title{
Adverse reactions from community directed treatment with ivermectin (CDTI ) for onchocerciasis and loiasis in Ondo State, Nigeria
}

\author{
O.A.Otubanjo ${ }^{1}$, G.O.Adeoye ${ }^{1}$, C.A.Ibidapo ${ }^{2}$, B.Akinsanya ${ }^{1}$, P.Okeke ${ }^{1}$, T. Atalabi ${ }^{1}$, E.T. Adejai ${ }^{3}$ \& \\ E. Braide ${ }^{4}$ \\ 1. Department of Zoology, University of Lagos, Akoka, Yaba, Lagos, Nigeria; adetoro2001@yahoo.com, \\ goa4567@yahoo.com, akinbami2000@yahoo.com \\ 2. Department of Zoology, Faculty of Science, Lagos State University, Ojo, Lagos, Nigeria; jokeibidapo@yahoo.com \\ 3. Onchocerciasis Section, Ministry of Health, Ondo State, Nigeria. \\ 4. Department of Biological Sciences, University of Calabar, Calabar, Cross River State, Nigeria; \\ ekanem_b@hotmail.com
}

Received 07-VI-2007. Corrected 30-VI-2008. Accepted 31-VII-2008.

\begin{abstract}
Onchocerciasis is an endemic disease in Ondo state, Nigeria. Community directed distribution of ivermectin is currently on-going in some local government areas of the state. Randomly selected persons ( 2 331 males and 2469 females) were interviewed using a modified rapid assessment procedure for Loa loa (RAPLOA) to assess community directed treatment with ivermectin. The retrospective study evaluated the coverage, impacts and adverse reactions to the drug treatment. A questionnaire was administered by house-to-house visit in six local government areas, implementing community directed treatment with ivermectin (CDTI) in this bioclimatic zone. A total of 2,398 respondents were reported to have participated in the treatment. The overall ivermectin coverage of $49.96 \%$ was recorded (range $0-52 \%$ in different communities). Adverse reactions from ivermectin administration were experienced in $38 \%$ of individuals. Diverse adverse reactions experienced included predominantly itching $(18.50 \%)$; oedema, especially of the face and the limbs $(8.2 \%)$; rashes $(3.4 \%)$ and body weakness (2.4\%). Expulsion of intestinal worms occurred in $0.96 \%$ of the respondents. The occurrence of adverse reactions in relation to age categories was statistically significant. Neither fatal nor severe adverse reactions were reported by respondents. Significantly, despite experienced adverse reactions, continued participation, acceptability and compliance to ivermectin treatment was expressed by the various communities. This attitude is in consonance with the African Programme for Onchocerciasis Control (APOC) objectives. Rev. Biol. Trop. 56 (4): 1635-1643. Epub 2008 December 12.
\end{abstract}

Key words: onchocerciasis, loiasis, adverse reactions, community directed treatment with ivermectin, rapid assessment procedure for Loa loa, African Programme for Onchocerciasis Control.

Onchoceriasis or river blindness, a major public health problem, afflicts 18 million people world wide, of whom $99 \%$ live in Africa south of the Sahara (Ety'ale 2001, 2002). The control of onchocerciasis is under the WHO programme of the African Programme for Onchocerciasis Control (APOC). This programme entails mass chemotherapy by community directed treatment with ivermectin (CDTI), following the free donation of the drug (Mectizan $\left.{ }^{\circledR}\right)$, by the manufacturer, Merck \&
Co. Inc. The use of ivermectin revolutionalized onchocerciasis control in Africa and the control programme is geared to reduce the transmission of the disease.

Meanwhile, a single annual dose treatment with ivermectin by community directed distributors forms the principal intervention in the control of the disease, Mild adverse reactions, including pruritus (itching), fever and rashes within the first 2-3 days of ivermectin administration have been variously documented 
(Gardon et al. 1997, Kipp 2003, WHO 2003). However, the diversity of adverse symptoms is complicated in regions of co-endemicity of onchocerciasis with loiasis. Serious complications, such as severe and sometimes fatal encephalopathic adverse reactions and coma in patients with onchocerciasis combined with high intensity of Loa loa have been reported (Chippaux et al. 1996, Gardon et al. 1997, Boussinesq et al. 1998). Also, ivermectin is contra-indicated in patients with trypanosomiasis and central nervous disorders, especially meningitis. In the absence of a clinical macrofilaricide, the risk of severe reactions threatens the success of the control programme in certain African communities with endemic loiasis.

Using rapid epidemiological mapping of onchocerciasis, the pattern of onchocerciasis endemicity in Ondo State, South western Nigeria was undertaken in 1994 by the State task force. Ondo State is in a bioclimatic zone, ranging from rainforest to savannah mosaic. It is highly endemic for onchocerciasis. Ivermectin administration started in 1994 under the auspices of the United Nations Children Education Fund in five local government areas. In June 2000, the African Programme for Onchocerciasis Control and communities directed treatment with ivermectin commenced in sixteen onchocerciasis endemic local government areas in the State.

\section{MATERIALS AND METHODS}

Study site: The study involved 60 communities in six selected local government areas in Ondo State, South Western Nigeria. The studied local government areas were Owo, Akure North, Ifedore, Akure South, Ondo East and Ondo West. The projected population of the state is about 2.9 million. Ondo state covers an area of 15600 square kilometers, lying in the bioclimatic zone, ranging from rainforest to forest, savanna mosaic to guinea savannah and mountainous areas. The study areas were randomly selected within the onchocerciasis endemic areas under mass ivermectin treatment. The main occupations in the State are farming and trading. Advocacy was established at all levels of government, prior to the commencement of the study.

A total of 4800 individuals (2 331 males and 2469 females), 18 years old and above were randomly selected and interviewed during the survey. A modified rapid assessment procedure for loiasis (TDR 2000) was administered by house to house visits in the study areas. The rapid assessment procedure for loiasis was used in establishing the local name, the history and occurrence of loiasis in the studied communities. The year/years of treatment and impacts of ivermectin administration were recorded for individuals interviewed.

Statistical analysis: The data obtained were statistically analyzed using the Chi-square test.

\section{RESULTS}

Of the 4800 individuals, 2398 were reported to have participated in the community directed treatment with ivermectin between the periods 1996 to 2004(Table 1). Amongst these participants, ivermectin had been administered only once in $1771(73.84 \%)$ of the treated respondents. The overall coverage of $49.96 \%$, ranging from $0-52 \%$ was reported in the different communities (Table 2). Participation and coverage in the community directed treatment with ivermectin was highest in Ifedore Local Government Area and least in Owo Local Government Area (Table 3). Both genders participated in a 1: 1 ratio in the community directed treatment with ivermectin within the various local government areas (Table 3). This study revealed that the age groups $21-30$ and $31-40$ were actively involved in community directed treatment with ivermectin programme in the State (Table 2). It was noted that participation in the community directed treatment with ivermectin was significantly age- related in some local government areas.

Adverse reactions to ivermectin experienced within the communities ranged from pruritus (itching); swelling or oedema of the body, particularly the face, stooling, general body pain, muscular or joint pain, rashes, body stiffness and general malaise occurring within 
TABLE 1

Summary of CDTI coverage from 1989-2004 in the studied population

$\begin{array}{cr}\begin{array}{c}\text { Duration } \\ 1989\end{array} \\ 1996 & \text { Female (\%) } \\ 1997 & 2(33.33) \\ 1998 & 10(35.71) \\ 1999 & 21(39.62) \\ 2000 & 43(42.57) \\ 2001 & 130(49.81) \\ 2002 & 302(47.86) \\ 2003 & 702(54.00) \\ 2004 & 11(68.75) \\ \text { Total } & 1221(50.92) \\ \text { WithoutCDTI } & 1248(51.96) \\ \text { Overall Total } & 2469(51.44)\end{array}$

$\begin{array}{rr}\text { Male }(\%) & \text { Total } \\ 1(100.00) & 1 \\ 1(100.00) & 1 \\ 4(66.67) & 6 \\ 18(64.29) & 28 \\ 32(60.38) & 53 \\ 58(57.43) & 101 \\ 131(50.19) & 261 \\ 329(52.14) & 631 \\ 598(46.00) & 1300 \\ 5(31.25) & 16 \\ 1177(49.08) & 2398 \\ 1154(48.04) & 2402 \\ 2331(48.56) & 4800\end{array}$

the first week of drug administration. These reactions were indicated to extend in some respondents for a period of 7-14 days. Adverse reactions occurred in various combinations. In most cases, 914 (38.15\%) respondents' experienced adverse reactions on ivermectin administration (Table 4).

The predominant overall adverse reaction in each community was itching (18.5\%). Itching occurring for 1-5 days was usually accompanied by other symptoms and may extend for two weeks in some areas. Swelling or oedema of the body, particularly the face $(8.1 \%)$, rashes $(3.4 \%)$, boils $(3.4 \%)$, headache and fever $(0.72 \%)$ were experienced by respondents in the various communities (Table 5). Generally, adverse reactions were experienced within 1-7 days. Stooling was experienced by $0.40 \%$ of individuals after ivermectin administration. The degree of adverse reactions varied in the different local government areas (Table 6), with Ifedore Local Government Area recording the highest level of occurrence of adverse reactions. Ondo East Local Government Area had the lowest record of adverse reactions.
Adverse reactions were high in the $21-30$ years age group with 154 (22.4\%) individuals. This was statistically significant $(\mathrm{P}>0.05)$. The age groups 50- 70 years and above recorded significant adverse reactions. However, adverse reactions were not significant in relation to the gender of the respondents. Within the gender, adverse reactions occurred in $51.10 \%$ and $48.80 \%$ males and females respectively. The ratio of male to female with adverse reactions was 1:1.06. Consequent to ivermectin treatment some respondents $(0.96 \%)$ experienced intestinal worm expulsion.

Loiasis endemicity in the communities ranged from low to moderate. The common name for loiasis in all the communities is "aran oju” (meaning eye worm).

\section{DISCUSSION}

Community directed treatment with ivermectin (CDTI) is the principal drug delivery strategy for onchocerciasis control. In Ondo State, ivermectin treatment control programme commenced in 1994, under the auspices of 


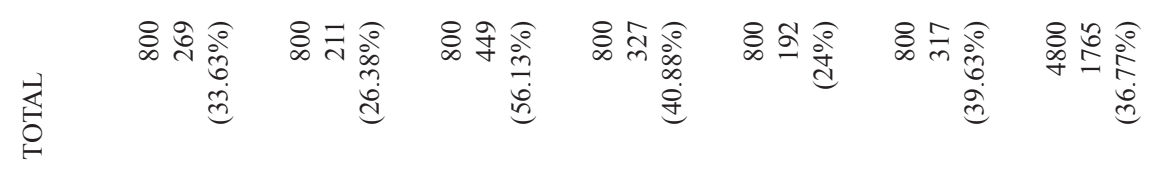

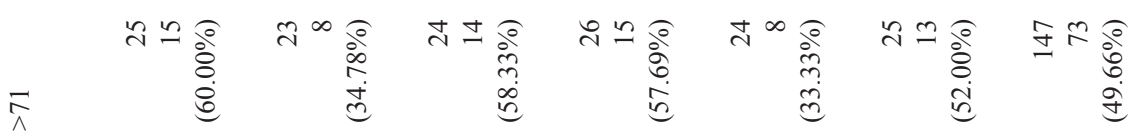

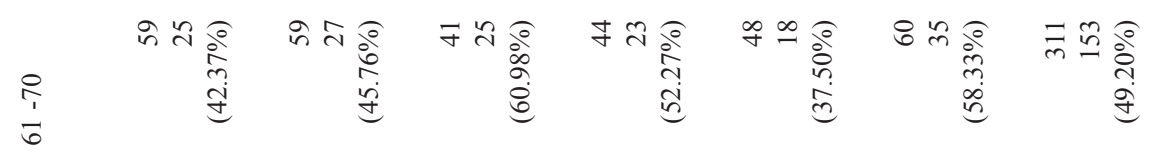

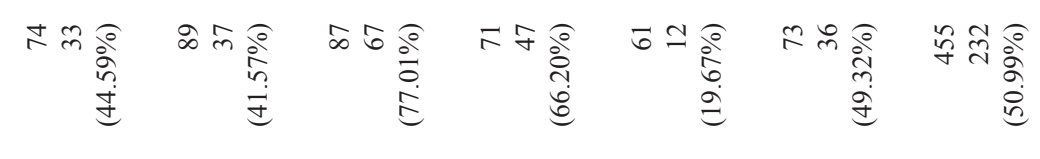

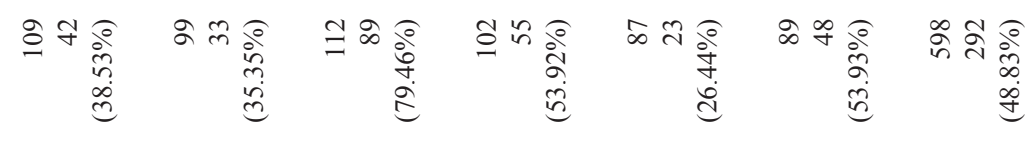

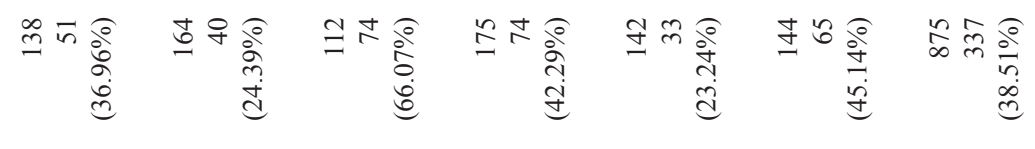

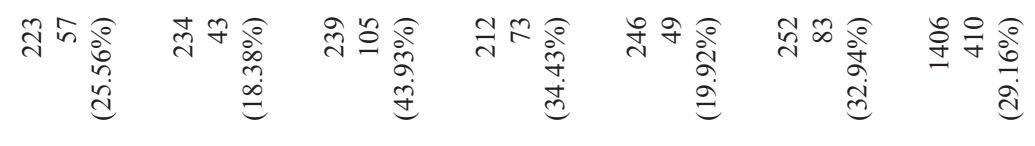

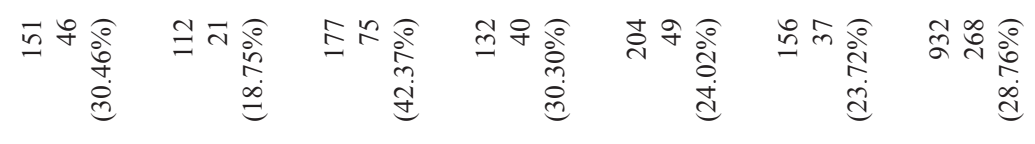

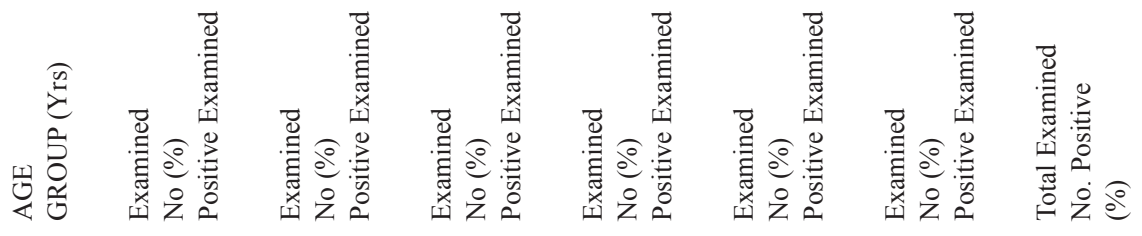

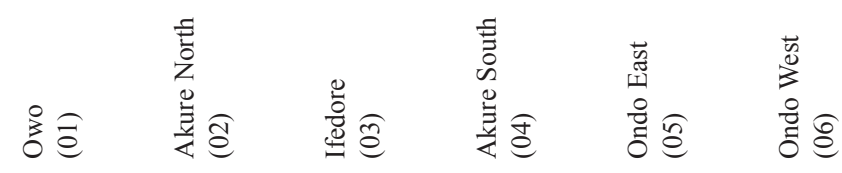


TABLE 3

CDTI coverage by sex in the six local government areas in Ondo State

\begin{tabular}{|c|c|c|c|c|}
\hline & & VERAGE RA & & \\
\hline & & Male & Female & TOTAL \\
\hline Owo ( 01) & Examined & 345 & 455 & 800 \\
\hline & No. (\%) Positive & $161(45.87)$ & $190(54.13)$ & $351(43.88)$ \\
\hline Akure North (02) & Examined & 443 & 357 & 800 \\
\hline & No. (\%) Positive & $271(61.04)$ & $173(38.96)$ & $444(55.50)$ \\
\hline Ifedore (03) & Examined & 343 & 457 & 800 \\
\hline & No. (\%) Positive & $93(27.10)$ & $120(26.30)$ & $213(26.63)$ \\
\hline Akure South (04) & Examined & 409 & 391 & 800 \\
\hline & No. (\%) Positive & $219(53.50)$ & $187(47.80)$ & $406(50.75)$ \\
\hline Ondo East (05) & Examined & 395 & 405 & 800 \\
\hline & No. (\%) Positive & $128(32.40)$ & $143(35.31)$ & $271(33.87)$ \\
\hline Ondo West (06) & Examined & 396 & 404 & 800 \\
\hline & No. (\%) Positive & $177(44.70)$ & $174(43.10)$ & $351(43.88)$ \\
\hline TOTAL & Examined & 2469 & 2331 & 4800 \\
\hline & No. (\%) Positive & $1177(47.80)$ & $1221(52.40)$ & $2398(49.95)$ \\
\hline
\end{tabular}

TABLE 4

Percentage adverse reactions in the six Local Government Areas in Ondo State

Local government areas

Owo LGA.

Akure North LGA

Ifedore LGA

Akure South LGA

Ondo East LGA

Ondo West LGA

TOTAL

\section{CDTI Count}

351

444

587

394

271

351

2398

$\begin{array}{cc}\begin{array}{c}\text { Adverse reactions } \\ \text { Count }\end{array} & \begin{array}{c}\text { Adverse reactions } \\ \text { Count }\end{array} \\ 128 & 36.47 \\ 257 & 57.88 \\ 224 & 38.16 \\ 106 & 26.90 \\ 79 & 29.15 \\ 120 & 34.19 \\ 914 & 38.12\end{array}$

United Nations in five local government areas. In June 2000, the African Programme for Onchocerciasis Control and ivermectin strategy became operational. The treatment coverage is still low. This report affirms a $49.95 \%$ community directed treatment with ivermectin in the study areas. African Programme for Onchocerciasis Control recommends at least a target of $65 \%$ therapeutic coverage annually. This study reveals that $2402(50.04 \%)$ of the respondents have not received ivermectin in the study area. A small percentage of the communities had achieved the target therapeutic coverage. A major reason for this is that community directed treatment with ivermectin is irregular and haphazard. 
TABLE 5

Adverse reactions experienced within the studied population

Adverse Reaction

Itching
Swelling
Stooling
Body Pain

Headache and Fever

Weakness

Boils/Rashes

Body Stiffness

\begin{tabular}{|c|c|c|c|c|c|c|}
\hline \multicolumn{6}{|c|}{ Local Government Areas in \% } & \multirow{2}{*}{ Total $\%$} \\
\hline 1 & 2 & 3 & 4 & 5 & 6 & \\
\hline 16.43 & 3.83 & 21.80 & 13.71 & 10.70 & 17.38 & 17.91 \\
\hline 6.52 & 2.92 & 3.92 & 6.60 & 9.59 & 10.54 & 7.93 \\
\hline 0.57 & - & 0.34 & 0.51 & 0.74 & - & 0.40 \\
\hline 1.70 & 0.23 & 0.85 & 1.02 & - & 1.14 & 0.85 \\
\hline- & 0.23 & 0.85 & 0.51 & 0.74 & - & 0.72 \\
\hline 1.42 & 0.90 & - & 3.05 & 2.95 & 1.99 & 2.29 \\
\hline 3.97 & 0.90 & 3.07 & 2.03 & 2.95 & 5.41 & 3.30 \\
\hline 0.85 & - & 0.17 & - & - & - & 0.28 \\
\hline
\end{tabular}

TABLE 6

Adverse reactions in the different Local Government Areas

\begin{tabular}{|c|c|c|c|c|}
\hline LOCAL GOVERNMENT & COUNT & $\begin{array}{c}\text { Adverse Reactions } \\
\text { YES }\end{array}$ & $\begin{array}{c}\text { \% WITHIN LG } \\
\text { CODE }\end{array}$ & $\begin{array}{c}\% \text { WITHIN } \\
\text { Adverse Reactions }\end{array}$ \\
\hline OWO & 800 & 100 & $12.50 \%$ & $7.75 \%$ \\
\hline AKURE NORTH LGA & 800 & 393 & $49.13 \%$ & $30.47 \%$ \\
\hline IFEDORE LGA & 800 & 529 & $66.13 \%$ & $41.00 \%$ \\
\hline AKURE SOUTH & 800 & 90 & $11.25 \%$ & $6.98 \%$ \\
\hline ONDO EAST & 800 & 60 & $7.50 \%$ & $4.65 \%$ \\
\hline ONDO WEST & 800 & 118 & $14.75 \%$ & $9.15 \%$ \\
\hline TOTAL & 4800 & $1290(53.79 \%)$ & & \\
\hline
\end{tabular}

N.B 2,398 respondents participated in CDTI.

Several problems currently associated with drug distribution coverage in the state includes, instability and disruption of the programme by state bureaucratic processes, fuel scarcity, fund disbursement and general lack of adequate commitment to the programme by local government coordinators. The lack of incentives for the community directed distributors and inaccessibility of some target communities are additional obstacles to drug distribution.

The success of African Programme for Onchocerciasis Control will depend on the sustenance of community directed treatment with ivermectin (Amazigo et al. 2002)
Adverse reactions to ivermectin occurred in $53.79 \%$ of respondents that participated in the drug treatment. There is no gender difference in their participation in the community directed treatment with ivermectin. Gender issues relating to community directed treatment with ivermectin constitute a challenge to African Programme for Onchocerciasis Control (Clemmons et al. 2002, Seketeli 2002). Within the study period, $1221(50.92 \%)$, females participated in the programme. Many respondents, 1771 (73.85\%) had only been administered the drug once, since the inception of the programme. This report establishes the low level 
and haphazard distribution of ivermectin in the study areas. However, the African Programme for Onchocerciasis Control recommends several years of annual ivermectin administration to effectively establish reduced transmission of onchocerciasis and thereby intercept the disease endemicity in the African region.

Adverse reactions experienced are varied and similar to those that has been documented in previous studies (Zea-Flores et al 1992, Burnham 1993, Baraka et al. 1995, Kipp et al. 2003). Significantly itching, oedema, boils and rashes were the reported adverse reactions. Host inflammatory responses had been indicated due to dying microfilariae and not by direct drug toxicity (Turner et al. 1994). No fatal, severe adverse reaction was reported in all the communities. The attitudes of individuals to adverse reactions and further treatment were non-conflicting. Similar reports have been documented (Baraka et al. 1995). Rapid procedure for loiasis is a useful tool in the continued rapid assessment of community prevalence of loiasis infection especially in areas of co-infection of loiasis with onchocerciasis.

According to the data, the prevalence of loiasis in all the communities was much below $40 \%$. The low endemicity of loiasis is considered to have low risk of adverse reactions during mass drug therapy with ivermectin (Tropical Disease Research 2002). The level of loiasis endemicity varied considerably between the local government areas and communities. The bioclimatic conditions of the different local government areas will affect the vector habitat, thereby impacting on the occurrence of the disease. While every community had a local name for the eye worm, Calabar swelling "awoka" (meaning moving about) was not common and tended to be less specific in the study areas.

Ondo State is hypoendemic for loiasis (Ibidapo et al. pers comm) and thereby ivermectin administration is considered relatively safe, despite some degree of reported adverse reactions. Severe or fatal adverse reactions were non existent.

The need to monitor adverse reactions following repeated ivermectin treatment is important to achieve the goals and objectives of African Programme on Onchocerciasis Control. Reduced adverse reactions from first to sixth rounds of treatments ( $40.6 \%$ to $15.6 \%$ ) in 890 individuals in Kwara State, in Nigeria have been recorded (Oyibo and FagbenroBeyioku 2003). They concluded that adverse reaction rates did not affect future participation in community directed treatment with ivermectin, as adequate community mobilization with health education messages were in place. Similar reports were documented by Kipp et al.2003 and Baraka et al. 1995. The pretreatment density of microfilariae in the skin influences the occurrence and intensity of adverse reactions. Continued drug delivery has been indicated to result in diminishing adverse reactions over time (Zea-Flores et al. 1992, Burham 1993). Despite some degree of adverse reactions experienced by respondents in this study, participation, acceptability and compliance to ivermectin administration was reasonable in consonance with the programmes' objectives.

The efficacy and action of ivermectin against filarial infections especially lymphatic filiariasis, many intestinal parasites, lice and scabies have been documented. Zea - Flores et al. 1992 reported 38\% worm expulsion on ivermectin administration in Guatamela. While this is considered to be an added advantage in ivermectin administration; affected individuals in many of the communities considered worm expulsion to be an adverse reaction. It is believed amongst the rural communities that a 'healthy' individual requires some degree of intestinal worm infection. Socio-culturally, worm expulsion was considered to be an adverse reaction by some rural respondents.

The occurrence of adverse reactions was predominant in the age group $21-30$. This may probably be due to the degree of exposure of ivermectin to this age bracket or may be influenced by the level of parasitism, since the intensity of microfilariae in the skin influence the nature and severity of adverse reactions.

This study revealed the need to increase ivermectin distribution to effectively achieve the targeted goals of the programme. The low 
endemicity of Loa loa in the study area permits the administration of ivermectin. A biannual mass drug administration in Ondo state has been recommended by Idowu 2004 as a consequence of the high endemicity of the disease in the region.

\section{ACKNOWLEDGMENTS}

This investigation was financially supported by Sight Savers International, Nigeria. We are grateful to the Onchocerciasis State coordinator, for his personal commitment to the success of this project.

\section{RESUMEN}

La oncocercosis es endémica en el estado Ondo, Nigeria. Se seleccionaron 4800 personas al azar para evaluar con encuesta retrospectiva la cobertura, efectos y reacciones al tratamiento farmacológico con ivermectina administrado por la misma comunidad. La cobertura global de ivermectina fue $50 \%$ con reacciones adversas en $38 \%$ de los individuos. Estas fueron comezón picazón (18\%), edema, especialmente de la cara y las extremidades (8\%), erupciones cutáneas (3\%) y debilidad (2\%); dependieron de la edad y no hubo reacciones más graves. La expulsión de las lombrices intestinales se produjo en $96 \%$ de los encuestados. A pesar de las reacciones adversas, hubo continuidad, aceptación y cumplimiento del tratamiento con ivermectina, en consonancia con los objetivos del Programa Africano para el Control de Oncocercosis (APOC).

Palabras clave: oncocercosis, loiasis, reacciones adversas, ivermectina, procedimiento de evaluación rápida para $L o a$ loa, Programa Africano para el Control de Oncocercosis.

\section{REFERENCES}

Amazigo, U.V., O.M. Obono, K.Y.Dadzie, J.Remme, J.Jiya, R.Ndyomugyenyi, I.B.Rongon, M.Noma \& A.Seketeli. 2002. Monitoring community directed treatment programmes for sustainability: lessons from the African Programme for Onchocerciasis Control (APOC). Ann Trop Med Parasit. 96: 575 - 592

Awadzi K., N.O.Opokn, E.T.Addy \& B.T.Quartey. 1995. The chemotherapy of onchocerciasis XIX: The chemical and laboratory tolerance of high dose ivermectin. Trop Med Parasitol. 46: 31 - 7

Burnham, G.M. 1993. Adverse reactions to ivermectin treatment for onchorcerciasis: results of a placebo -controlled, double -blind trial in Malawi. Trans R Soc Trop Med Hyg. 87: $313-7$

Baraka O.Z., A.K.Khier, K.M. Ahmend, M.M. Ali., A.E. el Mardi, B.M. Mahmoud, M.H.Ali., M.M.Homeida \& J.F.Williams.1995. Community based distribution of ivermectin in eastern Sudan: acceptability and early post-treatment reactions. Trans R Soc Trop Med Hyg. 9: 316-8.

Boussinesq M., I. Gardon , N.Gardon-Wendel, I.Kamgno, P.Ngoumou \& I.P.Chippaux 1998. Three probable cases of Loa loa encephalopathy following ivermectin treatment for onchocerciasis. Am J Trop Med Hyg. 58: 461-469.

Boussinesq M., I.Gardon., I.Kamgno \& S.D.S. Pion. 2001. Relationship between the prevalence and intensity of Loa loa infection in the Central Province of Cameroon. Ann Trop Med Parasit. 95: 495-507.

Clemmons L., U.V.Amazigo, A.C.Bissek, M.Noma, U.Oyene, U.Ekpo, J.Msuya-Mpanju, S.Katenga \& A. Seketeli. 2002. Gender issues CDTI of the African Programme for Onchocerciasis Control (APOC). Ann Trop Med Parasit. 96: S59-S74.

Chippaux J.P., M.Boussinesq, J. Gardon, N.Gardon-Wendel \& J.C.Ernould .1996. Severe adverse reaction risk during mass treatment with ivermectin in loiasisendemic areas. Parasitol. Today.12: 448-450.

Clemmons L, U.V.Amazigo, A.C. Bissek, M.Noma, U.Oyene, J.Msuya-Mpanju, S.Katenga \& A.Seketeli. 2002. Gender issues in community -directed treatment with ivermectin CDTI of the African Programme for Onchocerciasis Control (APOC). Ann Trop Med Parasit. 96: S59-S74.

Ety'ale D. 2001.Vision 2020: update on onchocerciasis community. Eye Health. 14: 19 - 20.

Etay'ale D. 2002. Eliminating onchocerciasis as a public health problem: the beginning of the end. Brit $\mathrm{J}$ Opthamol. 86: $844-846$

Gardon J., N.Gardon-Wendel, Demangangangue, J.Kamgno, J.P.Chippaux \& M. Boussinesq. 1997. Serious reactions after mass treatment of onchocerciasis with ivermectin in an endemic area for Loa loa infection. Lancet. 350: 18-22.

Idowu E.T. 2004. Epidemiological, clinco-parasitological and control studies of onchocerciasis in selected communities of Ondo state, Nigeria. Ph.D. Thesis, University of Lagos, Nigeria.

KippW., J.Bamhuhiiga, T.Rubaale \& D.W.Buttner. 2003. Adverse reaction to ivermectin treatment in Simulium neavei-transmitted onchocerciasis Am J Trop Med Hyg.69: 621-3. 
Oyibo W.A. \& A.F. Fagbenro-Beyioku. 2003. Adverse reaction following annual ivermectin treatment of onchcerciasis in Nigeria. Int J Infect Dis. 7: 156 -9

Seketeli A., G. Adeoye, A.Eyamba, E.Noruka , P.Drameh, U.V. Amazigo, M.Noma, F.Agboton, Y.Ahoton, O.Kale \& K.Y. Dadziek. 2002 The achievement and challenges of the African programme for onchocerciasis control (APOC). Ann Trop Med Parasit. 96: S15-S28.

Turner,P.F., K.A.Rocket, E.A.Otlesan.,H.Francis, K.Awadzi \& I.Clark. 1994. Inter leukin-6 and tumor necrosis factor in the pathogenesis of adverse reactions after treatment of lymphatic filariasis and onchocerciasis. J Infect Dis 69: 1071 - 5 .

Tropical Disease Research 2000.World Health Organization (WHO) Implementation and sustainability of community directed treatment with ivermectin. Geneva.
UNDP/ World Bank / WHO Special Programme for Research and Training in Tropical Disease. TDR / AFR / RP/96.1.

Tropical Disease Research (TDR). 2002. Guidelines for rapid assessment of Loa loa. UNDP/World Bank/ WHO.TDR/IDE/RAPLOA/02. 138 p.

World Health Organization 2003. Report of a multicountry study: The involvement of community-directed distributors of ivermectin in other health and development activities. UNDP/World Bank/WHO TDR/IDE/ CDD1/03.1.

Zea-Flores R, Richards FO Jr. Gonzalez - Peralta C, Castro Ramirez J, Zea-Flores G., Collins RC, Cupp E.1992. Adverse reactions after community treatment onchorcerciasis with ivermectin in Guatamela. Trans R Soc Trop Med Hyg. 86: 663-6. 
